ISSN: 2162-3104 Print/ ISSN: 2166-3750 Online

Volume 8, Issue 4 (2018), pp. 1636-1661

(C) Journal of International Students

http://jistudents.org/

doi: 10.5281/zenodo. 1468064

\title{
Relationships Between Stress and Psychosocial Factors with Sources of Help-Seeking Among International Students
}

\author{
Martin A. Swanbrow Becker \\ Florida State University, USA \\ Shengli Dong \\ Florida State University, USA \\ Julia Kronholz \\ Florida State University, USA \\ Chris Brownson \\ The University of Texas at Austin, USA
}

\begin{abstract}
This study explored the prevalence of stressors and their impact on distress for international students who did not seek help, those who sought either informal or professional help, and those who accessed both informal and professional help. Results indicated that international students underutilize professional support services when faced with serious stressors, such as assaults, and often do not seek help from any source for those stressors contributing most to their overall distress. Those endorsing higher levels of belonging, sense of coherence, mindfulness, academic and social integration and their sense of connection to their university tend to turn to informal sources of support, while those with lower levels tend to turn to professional supports. Implications for prevention, outreach, and clinical practice are discussed.
\end{abstract}

Keywords: help seeking, international students, psychological factors, support, stress 
University administrators increasingly shift their focus to the internationalization of higher education, defined as the incorporation of global dimensions into the purpose, function, and delivery of education (Knight, 2003). This educational philosophy aims to produce global pools of talent, recruit students from international countries, develop international branch campuses, foster exchange programs from students, staff, and faculty, and cultivate formal research partnerships between international institutions (Knight, 2004; Sanderson, 2008). As such, the number of international students utilizing U.S. higher education has grown tremendously in the past decades. To fully support international students, U.S. campuses must not only facilitate the delivery of academic content but also produce an environment where international students can thrive. International students confront unique stressors related to attending universities outside of their home country and coping with their new challenges as they transition to college. This transition becomes more complicated by the loss of their traditional sources of support, such as the proximity of their family and friends. This paper explores the impact of this loss of support by examining the sources of stressors and coping among international students who do not seek help as compared to those who turn to informal (e.g., family and friends) and / or professional help (e.g., counselors, psychologists).

\section{LITERATURE REVIEW}

The International Institute of Education (IIE, 2017) reported that in the last decade the number of international students studying in the United States increased by $85 \%$. Students travel to many countries around the world to study and the United States, in particular, serves as a leading destination of study for international students (IIE, 2015; Li, Wong, \& Toth, 2013). According to the IIE's 2015 Open Doors report, there were 974,926 international students studying in the United States during the 2014-2015 academic year. Understandably, international students significantly impact the U.S. economy, contributing over $\$ 30$ billion in 2015 (IIE, 2015). They also bring academic expertise and cultural diversity that are thought to enrich the learning experience for students broadly across campuses (Mamiseieshvili, 2012). 
While students come to study in the U.S. from countries all over the world, $50 \%$ of international students come from three countries: China (31\%), India (13\%), and South Korea (6.5\%) (IIE, 2015). As such, care should be taken when interpreting the results of research related to international students as studies examining the experiences of international students may reflect the experiences related to Asian culture in addition to those of being an international student per se.

\section{Stressors for International Students}

International students experience many of the same psychological stressors as domestic students (e.g., anxiety, depression, academic stressors), but also face very distinct stressors (Arthur, 1997). Yi, Lin, and Kishimoto (2003) proposed that international students' stressors could be divided into five categories, which include academic, financial, personal/social, vocational, and physical. Specifically, research informs that international students tend to report academic concerns, career concerns, anxiety, and depression as the most frequent psychological stressors ( $\mathrm{Li}$ et al., 2013; Mitchell, Greenwood, \& Guglielmi, 2007; Poyrazli, 2015; Yi et al., 2003). The focus on academic and career stress potentially emerges because international students may tend to prioritize academics over other personal concerns (Li et al., 2013).

Additional psychological stressors include isolation and discrimination (Arthur, 1997). Adjustment factors also may contribute to stress, as research suggests international students encounter difficulties regarding finances, culture shock, cultural misunderstandings, dietary restrictions, and lack of support from American peers (Heggins \& Jackson, 2003; Lin \& Yi, 1997; Olivas \& Li, 2006). These adjustment factors may contribute to psychological stressors such as anxiety and depression, and may also impact international students' relationships and supports for coping. Finally, English fluency impact academics in that the lack of English proficiency negatively affects academic persistence, putting international students at a higher risk for academic difficulties when compared to domestic students (Mamiseishvili, 2012; Poyrazli \& Kavanaugh, 2006). The findings demonstrating the psychological stressors experienced by international students highlights the need to better understand how social connection impacts international student coping with stressors, particularly as their stressors relate to isolation, discrimination, and cultural differences. 


\section{International Students' Coping with Stressors}

Research suggests that international students may cope in different ways than domestic students both in terms of their seeking out help from others and their internal personal attributes or resources. With regard to external sources of support, Alavi, Shafeq, Geramian, and Ninggal (2104) found that international students may prefer to cope with psychological or adjustment stressors independently, or may prefer to turn to significant others or peers in order to address their stressors, rather than professional sources of support. As such, they may only turn to professional help when they do not gain positive results from social supports, or they are unable to resolve problems by themselves. Brownson, Swanbrow Becker, Shadick, Jaggars, and Nitkin-Kaner (2014) determined that while international students experience unique stressors, they also appear to have helpful means of coping or resilience as they reported fewer thoughts of suicide during their lifetime than domestic students. The authors highlighted the challenges of interpreting the results of international students self-reports, however, in that low reports of suicidal thoughts may not provide an accurate summary of international students' true experience. The authors noted that the results of this particular study might be attributed to international students' unfamiliarity with talking about mental health issues in the way presented in the study, that international students may experience distress in a different way than what was offered by survey response, or cultural misinterpretation (Brownson et al., 2014).

In times of distress, international students tend to turn first to professors, friends, or medical professionals rather than the university counseling center, posing a challenge for counseling center outreach initiatives (Aubrey, 1991; Bradley, Parr, Lan, Bingi, \& Gould, 1995; Brownson et al., 2014). Hwang, Bennett, and Beauchemin (2014) found, however, that faculty and staff served as the most frequent referral source for international students who presented to counseling. It seems, the authors state, that international students "tend not to seek help by themselves, but are referred to by authority figures" (p. 351). Among those international students who told others about their suicidal thoughts, only $43 \%$ were referred to professional help by the first person they told, yet of those referred, $75 \%$ followed up to receive professional assistance (Brownson et al., 2014). These studies suggest that social networks influence international student help-seeking behaviors and that better understanding the relationship between stress and coping among those who seek help and those who do not could inform campus outreach and prevention efforts. 
Along with help-seeking behavior among international students, the current study also explores the internal, personal resources of international students that may impact their help-seeking behavior, including a disposition toward mindfulness, sense of coherence, sense of belonging, academic and social connectedness, and connection to their university. Preliminary research has demonstrated evidence of relationships between these constructs related to internal, personal resources and international student help-seeking behaviors (e.g., Cho \& Yu, 2015; Du \& Wei, 2015; Glass, 2014). For example, mindfulness practice evidenced an inverse relationship with psychological distress among international students, suggesting that international students who practice mindfulness during stressful periods tend to report lower levels of distress (Masuda, Wendell, Chou, \& Feinstein, 2010). The construct of sense of coherence (Antonovsky, 1993), defined as the ability to cope with stressful life events successfully, provides another factor that may impact international students' help-seeking, yet limited research exists in regards to its utility for international students. Initial investigations, however, indicate that international students tend to report a lower sense of coherence when compared to domestic students (Grayson, 2007, 2008). This suggests that international students may feel less capable than others to take on the challenges of personal or academic stressors.

Social connectedness and sense of belonging constitute two concepts frequently cited in the literature regarding international student coping. Tinto (1988) referred to social and academic integration as integral to student's developing coping strategies in universities. One study found that international students tended to seek support from family and co-nationals (others from the same country of origin) during stressful periods rather than mental health professionals (Yan \& Berliner, 2011). This suggests that social connectedness serves as a major resource that impacts psychological distress. Further supporting these findings, recent studies found social connectedness significantly predicted resiliency (Sabouripour \& Roslan, 2015) and subjective well-being ( $\mathrm{Du} \& \mathrm{Wei}, 2015)$ for international students. Finally, research indicates that participation in social events (such as socialization with domestic students) significantly predicted positive social adjustment in a population of international students (Campbell, 2011; Glass, 2014). The body of research, though limited, seems to indicate that mindfulness, belongingness, and connectedness are important personal resources for international students' psychological well-being. The generalizability of most of the previous studies, however, is limited as they 
utilized relatively small international student samples within one university setting.

\section{Help-Seeking for Counseling Services}

Despite the increase in enrollment of international students in U.S. institutions, this population historically underutilizes counseling services (Brownson et al., 2014; Pedersen, 1991; Nillson, Berkel, Flores, \& Lucas, 2004; Poyrazli, 2015). The underrepresentation in counseling, however, does not necessarily indicate lower psychological distress for this population (Hwang et al., 2014). For example, although international students reported fewer thoughts of suicide over their lifetime than others, they were just as likely to have seriously considered or attempted suicide in the most recent 12 month period (Brownson et al., 2014). Despite having similar rates of current suicidal thoughts and experiences, international students were less likely to seek counseling services when compared to other college student groups (Brownson et al., 2014). Research has offered a myriad of reasons to explain the underrepresentation of international students seeking counseling services, ranging from lack of knowledge regarding counseling services (Wilson, Deane, Biro, \& Ciarrochi, 2003) to racial discrimination (Yi et al., 2003). Hwang and colleagues (2014) suggested three overarching reasons for the underutilization of counseling services from international students: the stigma of seeking mental health services, a lack of knowledge about counseling services, and culturally inappropriate services.

Rickwood, Deane, Wilson, and Ciarrochi (2005) proposed that negative attitudes towards counseling and stigma of mental health services constitute the main obstacles for international students in seeking help. Negative attitudes may stem from negative beliefs about the quality of help. This may contribute to the unwillingness to admit psychological problems for fear of tarnishing the student's reputation or the reputation of their home country (Pedersen, 1991). Wisdom, Clarke, and Green (2006) proposed that most young people do not want to be seen by others as having mental problems, which may contribute to the low rate of service utilization.

In addition to a negative stigma towards counseling services, international students may be unfamiliar with counseling (Mori, 2000), and may feel uncomfortable interacting in a one-on-one situation with a stranger (Arthur, 1997). International students may be less knowledgeable about university counseling center services than domestic students, which includes a lack of awareness about the existence of the counseling center, the location of the counseling center, and the services provided (Wilson et al., 2003; Wisdom et al., 2006). Mitchell and colleagues (2007) found that international 
students tended to be less likely to seek help when not in crisis as compared to domestic students, but more likely to seek help when in crisis. This indicates that rather than seeking help when symptoms of stress first emerge, international students seek help when the level of distress causes significant impairment in their academic, social, and relational experiences. It also suggests that counseling centers may be the last resort for international students and, as such, psychological symptoms may be severely escalated (Lin, 1996). These factors leading to underutilization of counseling services for international students could be potentially attributed to the acculturation level of international students. Zhang and Dixon (2003) found that international students' attitude of help-seeking was positively related to their level of acculturation in the host country.

While previous studies examined barriers related to help-seeking attitudes and behaviors among international students, relatively few investigations focused on the impact of intrinsic resources (e.g., mindfulness, sense of coherence, etc.) on help-seeking behavior. Among studies examining the intrinsic resources, most of the studies utilized relatively small samples within one university sample, limiting the generalizability of study results. Further, to the best of our knowledge, no study has examined the intrinsic resources comprehensively in relation to diverse help-seeking attitudes and behaviors among international students.

\section{Purpose of Current Study}

The purpose of this paper is to address the gap in the research regarding the impact on stress related to the lack of support and help-seeking behaviors of international students in higher education, using a large, national sample. The research questions are as follows: 1. What are the differences between international students not seeking help and those seeking informal and / or professional help in terms of sources, intensity, and frequency of stressors? 2. What are the differences (means, effect size) in terms of psychosocial factors, including mindfulness, belongingness, sense of coherence, academic and social participation/integration, and connection to university among international students comparing those not seeking help and those seeking informal and / or professional help?

Examining the help-seeking attitudes and behaviors of international students is critical to better understand the needs of this population, and provides important implications for administrators and practitioners regarding professional service delivery as well as outreach and prevention. 


\section{RESEARCH METHOD}

\section{Procedure}

Data for this study was acquired from the National Research Consortium of Counseling Centers in Higher Education (Research Consortium) during the spring of 2011. College students responded to a 79question web-based survey with items including demographics, mental health history, history of seeking help for mental health issues, psychosocial factors such as trait mindfulness, sense of belongingness, sense of coherence, academic and social participation, connection to their university, and experiences related to baseline function and then how they changed during a stressful period within the past 12 months. These items were developed by the Research Consortium with consultation from representatives at each of the participating institutions of higher education as well as by experts in the field of college student mental health.

Four-year colleges and universities choosing to participate in the study sent email invitations to their students. A stratified, random, non-clinical sample of 100,492 students across 73 participating institutions was selected. In order to encourage significant participation between schools while also allowing for larger schools to survey a greater representation of their students, for institutions with more than 5,000 undergraduates, 1,000 students were selected randomly; for those with 500 to 4,999 students enrolled, 500 students were selected randomly; and for those with fewer than 500 undergraduates, all students were surveyed. The same sample size guidelines were used to select graduate students. Following the initial request to complete the survey, students were sent two follow-up emails. The undergraduate and graduate combined response rate was $26 \%$, for a total sample of 26,292 students. The institutions were geographically diverse with campuses located in the Northeast (21\%), Northwest $(7 \%)$, West $(10 \%)$, Midwest (25\%), Southeast (12\%), Southwest, (15\%) Central (4\%), and Mid-Atlantic (6\%).

\section{Sample Size}

This study examines the experiences of the 2,596 students identifying as international students. Females account for $48 \%$ of the sample, males accounted for $52 \%$, and $0.1 \%$ identified as transgender. Most students identified as graduate students (77\%), heterosexual $(88 \%)$ and identified their ethnicity as Asian (55\%). The mean age of the respondents was 27 years old, with a standard deviation of 6.06. Regarding nationality, most identified their country of origin as China $(27 \%)$ and India $(15 \%)$, with 
others identifying with the countries in the following regions: Asia (other than China or India) (20\%), Africa (5\%), Eastern Europe / Russia (5\%), Middle East (5\%), North American (other than the United States) (5\%), South America (5\%), Western Europe (5\%), Caribbean (2\%), Central America (1\%), Australia / New Zealand (1\%) and 6\% of international students did not identify a country of origin. See Table 1 for demographic information.

Table 1. Sample demographics: Grade classification, sex, ethnicity, sexual orientation, and age.

Grade Classification

Freshman

Sophomore

Junior

168

Senior

Graduate Student

Sex

Female

$\begin{array}{cc}1,230 & 48 \\ 1,356 & 52 \\ 3 & <1\end{array}$

Male

Transgender

Ethnicity

African American, of African Descent, African, of Caribbean descent, or Black

Asian or Asian American

Caucasian, White, of European Descent, or European

420

Hispanic, Latino or Latina

178

Middle Eastern or East Indian

Multiple race/ethnicity

96

4

Sexual Orientation

Bisexual 
Gay or Lesbian

Heterosexual

\section{Measures}

To determine who students turned to for help during their reported stressful period, they were asked "from whom did you seek help or support in dealing with this stressful period? (select all that apply)". Responses indicating that students turned to family members, friends, peers, roommates, romantic partners, academic advisers, coaches, instructors, resident advisors were coded as "informal help" while those selecting psychologist, counselor, social worker, psychiatrist, medical provider, alternative medical provider, or clergy were coded as "professional help". Students were then assigned to one of the following four groups for data analysis. 1) The "no help" group did not seek any help in dealing with the stressful period. 2) The "informal help" group sought help only from informal sources. 3) The "professional help" group sought help only from professional sources. 4) The "both informal and professional help" group sought help from both informal and professional sources.

Contributors to the stressful period and contributions to overall distress. The survey prompted international students to "reflect on the most stressful period of time you have experienced in the past 12 months, including the present day." They were then asked to select as many of the descriptors of stressful events that best described the contributors to the stressful period. See Table 2 for a list of the 20 categories of stressful events respondents could select from. They were then asked to rate for each stressful event selected "to what extent did this contribute to your level of stress or feelings of distress?" Response options ranged from 1 to 5 with markers including 1) Not at all, 3) Moderately, 5) Very much.

\section{Mindfulness Scale}

The Cognitive and Affective Mindfulness Scale-Revised (Feldman, Hayes, Kumar, Greeson, \& Laurenceau, 2007; CAMS-R) is a 10-item, self-report assessment measuring the construct of mindfulness among the sample. The scale has a total score range of 10-40, and includes items such as, "It is easy for me to concentrate on what I am doing", and "I can tolerate emotional 
pain". This scale had acceptable internal reliability with this sample (Cronbach's $\alpha=.75$ ).

\section{Belonging}

To assess the extent to which participants felt a sense of belonging to others, the survey asked students to respond to four questions. The first question asked, "How understood by others do you feel?" with response options of 1 to 5 with markers including 1) Not at all understood, 3) Moderately understood, 5) Very much understood. The second question asked, "How cared for by others do you feel?" with response options of 1 to 5 with markers including 1) Not at all cared for, 3) Moderately cared for, 5) Very much cared for. The third question asked, "How much do you feel that you can count on others?" with response options of 1 to 5 with markers including 1) Not at all able to count on others, 3) Moderately able to count on others, 5) Very much able to count on others. The fourth question asked, "How comfortable do you feel making new connections with others?" with response options of 1 to 5 with markers including 1) Not at all comfortable, 3) Moderately comfortable, 5) Very comfortable. Respondents were asked about their sense of belonging during their baseline functioning and during the stressful time to assess for how this construct changes with the introduction of stress. These questions demonstrated acceptable reliability in the current sample for both baseline functioning and during the stressful time (Cronbach's $\alpha=.72$ and .80 , respectively).

\section{Sense of Coherence}

To assess for adaptive functioning during times of stress among participants, this study asked participants to respond to five questions that relate to the three components of Antonovsky's Sense of Coherence scale, including the constructs that their life is comprehensible, manageable and meaningful (Antonovsky, 1993). The questions included, "When approaching the challenges of daily life: a) "How critical are you of yourself?"; b) "How capable are you of managing your daily challenges?"; c) "How motivated are you to manage your daily challenges?"; d) "How meaningful do you view your life to be?"; and e) "To what extent are you able to understand what must be done to face the challenges of daily life?" Response options ranged from of 1 to 5 with markers of 1) Not at all, 3) Moderately, 5) Very. These questions demonstrated adequate reliability in the current sample for both baseline functioning and during the stressful time (Cronbach's $\alpha=.65$ and .64, respectively). 


\section{Social and Academic Participation / Integration}

Respondents were asked to indicate the extent to which they actively participated as either a member or in a leadership role across 11 activities. The activities in the "social participation" category include participation in arts organizations; fraternity or sorority; informal groups with shared interests (e.g., exercise, entertainment, food, drink); international, ethnic or cultural organizations; intramural or club sports; paid employment; political, social-action or student government organizations; religious organizations; service or social organizations; and varsity athletic teams. To assess for "academic participation" respondents were asked directly about academic or professional organizations. Respondents were also asked to indicate "How important is this activity or group as a social network in your life?" with response options ranging from of 1 to 5 with markers of (1) Not at all important, (3) Moderately important, (5) Very important.

To assess the total level and importance of participation across groups, 1 point was assessed for membership in the category and 2 points were assessed for assuming a leadership role. The score was then multiplied by the importance of the group to determine the total combined level and importance of participation in each activity. To determine the total level and importance of social participation, scores were added across each social activity to create a total score.

\section{Connection to University}

To assess participant connection to their university, they were asked during their reporting of baseline functioning "To what degree do you feel connected to your college or university?" with response options ranging from of 1 to 5 with markers of (1) Not at all connected, (3) Moderately connected, (5) Very connected.

\section{Data Analysis}

To assess differences in terms of type and frequency of stressors among students across the four levels of help-seeking, a Chi-Square analysis was conducted to analyze the categorical data. An ANOVA analysis was utilized to evaluate the impact of the continuous predictor variables, including the differences in intensity of the stressors across the four groups as well as to assess for differences in mindfulness, belonging, sense of coherence, academic and social participation / integration and connection to their university. Prior to conducting the Chi-Square and ANOVA tests, the assumptions for analyses were checked to confirm that no violation of test assumptions occurred. Due to the potential impacts of multilevel effects 
based on the nested nature of the data (e.g., student data grouped within school level data), a preliminary MANOVA analysis was completed to determine the impact of school-level data on the outcome variables.

\section{RESULTS}

\section{Preliminary Analysis}

To determine the potential impact of school level data on student level outcomes a MANOVA analysis was run to examine differences across schools based on the outcome variables. Results indicate a small effect size for each outcome variable, including Mindfulness $(F(72,2,034)=0.96, p=$ $\left..586, \eta^{2}=.033\right)$; Belongingness $\left(F(72,2,034)=1.36, p=.026, \eta^{2}=.046\right)$; Sense of Coherence $\left(F(72,2,034)=1.32, p=.039, \eta^{2}=.045\right)$; Academic Integration $\left(F(72,2,034)=1.44, p=.010, \eta^{2}=.049\right)$; Social Integration $\left(F(72,2,034)=1.75, p<.001, \eta^{2}=.058\right) ;$ and Connectedness to School $\left(F(72,2,034)=1.17, p=.160, \eta^{2}=.040\right)$. These findings suggest that school level data had a small impact on student outcomes. Based on this preliminary analysis, the follow results focus on student level data.

\section{Sources of Stress Across Levels of Help-Seeking}

Table 2 shows the percentage of international students choosing each of the four categories of help for each of the stressors noted. International students tended to rely on informal help in greater percentages than other sources of help and sought a range of informal help when confronted with most of the stressors listed, from $32 \%$ of those experiencing a sexual assault to $75 \%$ of those experiencing academic concerns. They rarely sought only professional help for support during the stressful time, with the highest percentages for Sexual Assault (11\%), Gender Identity Concerns (5\%), and Emotional Health Problems (5\%). International students tended, however, to supplement their informal help with professional help at the highest rates for support with the suicide of a close person, sexual assault, and relationship violence $\left(42 \%, 37 \%\right.$, and $32 \%, \chi^{2}(3)=31.378,33.417$ and $36.622, p<.001$, respectively). In fact, the only time international students sought a combination of informal and professional help at higher rates than informal help alone was when seeking help for sexual assault. International students showed the highest rates of avoiding help from all sources for Relationship Violence (27\%), Sexual Orientation Concerns (26\%), Sexual Assault (21\%), and Drugs and Alcohol (21\%). 


\begin{tabular}{|c|c|c|c|c|c|}
\hline Stressor & $\begin{array}{c}\text { Not } \\
\text { Seeking Help } \\
(\%) / \\
\text { (standardized } \\
\text { residuals) }\end{array}$ & $\begin{array}{c}\text { Seeking Informal } \\
\text { Help } \\
(\%) / \\
\text { (standardized } \\
\text { residuals) }\end{array}$ & $\begin{array}{c}\text { Seeking } \\
\text { Professional Help } \\
(\%) / \\
\text { (standardized } \\
\text { residuals) }\end{array}$ & $\begin{array}{l}\text { Seeking Both } \\
\text { Professional and } \\
\text { Informal Help } \\
(\%) / \\
\text { (standardized } \\
\text { residuals) }\end{array}$ & $x^{2}$ \\
\hline Suicide of close person & $11(-0.8)$ & $47(-1.3)$ & $0(-0.6)$ & $42(5.3)$ & $31.378^{*}$ \\
\hline Sexual assault & $21(0.3)$ & $32(-2.1)$ & $11(2.7)$ & $37(4.5)$ & $32.417^{*}$ \\
\hline Relationship violence & $27(1.3)$ & $41(-2.3)$ & $0(-0.8)$ & $32(5.4)$ & $36.622 *$ \\
\hline Gender ID concerns & $14(-0.5)$ & $55(-1.0)$ & $5(0.9)$ & $27(3.3)$ & $12.725^{* *}$ \\
\hline Physical health problems & $13(-1.7)$ & $57(-2.6)$ & $4(2.3)$ & $25(9.2)$ & $108.512^{*}$ \\
\hline Drugs/Alcohol & $21(0.3)$ & $50(-1.3)$ & $4(0.8)$ & $25(3.0)$ & $11.514^{* *}$ \\
\hline Legal problems & $15(-0.5)$ & $60(-0.9)$ & $3(0.3)$ & $23(3.3)$ & $12.314^{* *}$ \\
\hline Emotional health problems & $19(0.3)$ & $54(-3.1)$ & $5(3.0)$ & $22(7.3)$ & $78.559^{*}$ \\
\hline Other trauma & $7(-1.9)$ & $68(-0.4)$ & $4(0.9)$ & $21(3.6)$ & $18.321^{*}$ \\
\hline Discrimination & $16(-0.6)$ & $65(-0.9)$ & $2(-0.3)$ & $17(3.9)$ & $17.844^{*}$ \\
\hline Family problems & $15(-1.4)$ & $65(-1.6)$ & $4(2.5)$ & $16(5.9)$ & $53.783^{*}$ \\
\hline Death of close person & $9(-2.6)$ & $70(-0.3)$ & $4(2.3)$ & $16(3.8)$ & $28.368^{*}$ \\
\hline Problems at work & $13(-2.0)$ & $72(0)$ & $1(-1.0)$ & $14(3.3)$ & $17.933^{*}$ \\
\hline Problems of a close person & $13(-1.3)$ & $71(-0.2)$ & $2(-0.4)$ & $14(2.6)$ & $9.202 * *$ \\
\hline Sexual orientation concerns & $26(1.2)$ & $57(-1.1)$ & $2(0.2)$ & $14(1.5)$ & 5.178 \\
\hline $\begin{array}{l}\text { Romantic relationship } \\
\text { problems }\end{array}$ & $16(-1.4)$ & $69(-0.9)$ & $2(0.5)$ & $13(4.6)$ & $30.471^{*}$ \\
\hline Life transition & $13(-2.8)$ & $72(-0.1)$ & $2(0)$ & $13(4.5)$ & $35.429^{*}$ \\
\hline Friendship problems & $12(-2.7)$ & $73(0.1)$ & $2(0.5)$ & $13(3.4)$ & $21.876^{*}$ \\
\hline Financial problems & $16(-1.1)$ & $71(-0.4)$ & $2(0.5)$ & $11(2.7)$ & $12.258^{* *}$ \\
\hline Academics & $17(-1.7)$ & $75(1.3)$ & $2(-1.2)$ & $7(-0.8)$ & $24.119^{*}$ \\
\hline
\end{tabular}

\section{Contributions of Stressors to Overall Distress}

In addition to the source of stress, this study investigated the reported contribution to the overall distress of each stressor. See Table 3. Among participants who experienced family problems, those who sought both professional and informal help reported that the problems contributed more to their distress than students who sought either informal or professional help alone $(F(3,371)=2.67, p<.05)$. For the participants who experienced emotional health problems and academic problems, those seeking professional help as their sole source of support reported these stressors contributed more to their distress than those seeking informal help or not seeking help at all $(F(3,199)=5.58, p<.01$, and $F(3,1841)=3.05, p<.05$, respectively). Results suggest that among the individuals who encountered physical health problems, those who sought professional help alone or in combination with informal help may experience a higher contribution to their distress than those not seeking help or seeking informal help alone. $(F(3,205)=2.57, p=.055)$. No significant difference in contribution to overall distress was found for other life stressors. 
Table 3. A comparison of the contributions to distress across source of help-seeking groups based on stressor encountered.

\begin{tabular}{|c|c|c|c|c|c|}
\hline Stressor & $\begin{array}{c}\text { Not Seeking } \\
\text { Help }\end{array}$ & $\begin{array}{c}\text { Seeking } \\
\text { Informal } \\
\text { Help }\end{array}$ & $\begin{array}{c}\text { Seeking } \\
\text { Professional Help }\end{array}$ & $\begin{array}{l}\text { Seeking Both } \\
\text { Professional and } \\
\text { Informal Help }\end{array}$ & $F(d f)$ \\
\hline Suicide of close person & 4.5 & 4.0 & No respondents & 3.3 & $\begin{array}{c}F(2,16)=.78 \\
p=.477\end{array}$ \\
\hline Sexual assault & 4.5 & 3.2 & 2.5 & 3.4 & $\begin{array}{c}F(3,15)=.76 \\
p=.534\end{array}$ \\
\hline Relationship violence & 3.6 & 4.1 & No respondents & 4.1 & $\begin{array}{c}F(2,32)=.45 \\
p=.642\end{array}$ \\
\hline Gender ID concerns & 4.0 & 3.9 & 5.0 & 2.3 & $\begin{array}{c}F(3,18)=2.46 \\
p=.096\end{array}$ \\
\hline Physical health problems & 3.4 & 3.5 & 3.9 & 3.9 & $\begin{array}{c}F(3,205)=2.57 \\
p=.055\end{array}$ \\
\hline Drugs/Alcohol & 3.0 & 3.6 & 2.0 & 2.7 & $\begin{array}{c}F(3,19)=.91 \\
p=.456\end{array}$ \\
\hline Legal problems & 4.7 & 3.6 & 3.0 & 3.7 & $\begin{array}{c}F(3,36)=1.2 \\
p=.322\end{array}$ \\
\hline Emotional health problems & 4.1 & 3.5 & 4.3 & 4.0 & $\begin{array}{c}F(3,199)=5.58 \\
p=.001\end{array}$ \\
\hline Other trauma & 3.8 & 3.9 & 3.0 & 3.7 & $\begin{array}{c}F(3,50)=.36 \\
p=.779\end{array}$ \\
\hline Discrimination & 4.3 & 3.7 & 4.0 & 3.8 & $F(3,126)=1.85$ \\
\hline Family problems & 3.9 & 3.7 & 3.7 & 4.1 & $\begin{array}{c}F(3,371)=2.67 \\
p=.047\end{array}$ \\
\hline Death of close person & 3.5 & 4.2 & 4.3 & 4.4 & $\begin{array}{c}F(3,151)=2.39 \\
p=.071\end{array}$ \\
\hline Problems at work & 4.3 & 3.9 & 4.0 & 4.0 & $\begin{array}{c}F(3,260)=1.68 \\
\quad p=.172\end{array}$ \\
\hline Problems of a close person & 3.9 & 4.0 & 3.5 & 4.1 & $\begin{array}{c}F(3,128)=.26 \\
p=.855\end{array}$ \\
\hline Sexual orientation concerns & 4.4 & 3.8 & 5.0 & 3.2 & $\begin{array}{c}F(3,37)=1.41 \\
p=.256\end{array}$ \\
\hline Romantic relationship problems & 4.2 & 4.0 & 4.3 & 4.0 & $\begin{array}{c}F(3,523)=.69 \\
p=.560\end{array}$ \\
\hline Life transition & 4.1 & 4.1 & 3.8 & 4.2 & $\begin{array}{c}F(3,509)=.53 \\
p=.664\end{array}$ \\
\hline Friendship problems & 4.0 & 3.7 & 4.1 & 3.6 & $\begin{array}{c}F(3,337)=1.34 \\
\quad p=.260\end{array}$ \\
\hline Financial problems & 4.1 & 3.9 & 3.7 & 3.9 & $\begin{array}{c}F(3,623)=1.32 \\
p=.266\end{array}$ \\
\hline Academics & 4.0 & 4.1 & 4.3 & 4.2 & $\begin{array}{c}F(3,1,841)=3.05 \\
p=.028\end{array}$ \\
\hline
\end{tabular}

Note. Contributors to distress is the mean response of those students endorsing the stressor listed on a Likert Scale where $1=$ "Not at all", $3=$ "Moderately" and 5 = "Very much"

\section{Contributions of Stressors to Overall Distress}

In addition to the source of stress, this study investigated the reported contribution to the overall distress of each stressor. See Table 3. Among participants who experienced family problems, those who sought both professional and informal help reported that the problems contributed more to their distress than students who sought either informal or professional help alone $(F(3,371)=2.67, p<.05)$. For the participants who experienced emotional health problems and academic problems, those seeking professional help as their sole source of support reported these stressors contributed more to their distress than those seeking informal help or not 
seeking help at all $(F(3,199)=5.58, p<.01$, and $F(3,1841)=3.05, p<.05$, respectively). Results suggest that among the individuals who encountered physical health problems, those who sought professional help alone or in combination with informal help may experience a higher contribution to their distress than those not seeking help or seeking informal help alone. $(F(3,205)=2.57, p=.055)$. No significant difference in contribution to overall distress was found for other life stressors.

Table 4. Comparison of psychosocial factors across the help-seeking groups.

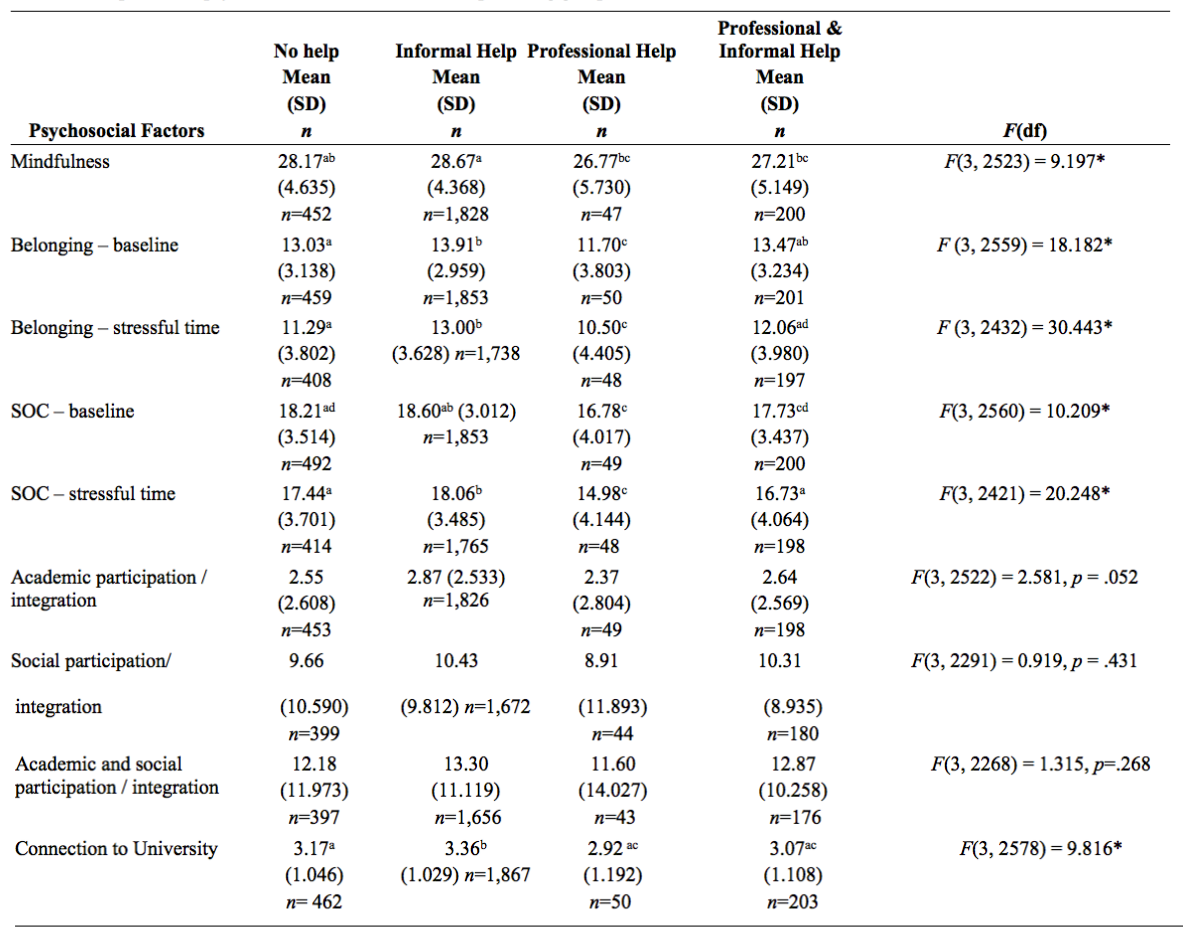

Note. Mean scores that do not share superscripts differ at $p<.01$.

${ }^{*} p<.001$

\section{The Impact of Psychosocial Factors on Distress}

In general, the participants who sought informal help reported the highest levels of all the psychosocial measures: mindfulness, sense of belongingness both during the baseline and the stressful time period, sense of coherence both during baseline and stressful time period, academic and social integration, and connection to the university. 
The participants seeking only informal help had significantly higher levels of mindfulness scores as compared to those who sought only professional help and those who sought both professional and informal help (Means of 28.67, 26.77, and 27.221, respectively; $F(3,2523)=9.197, p<$ $.001)$. See Table 4 . The participants who sought only professional help had the lowest sense of belongingness at baseline $(F(3,2559)=18.182, p<$ .001 ), while those who sought informal help either alone or in combination with professional help had the highest levels (Means of 11.70, 13.91, and 13.47, respectively), with this trend carrying over to their responses during the stressful time (Means of 10.50, 13.00, and 12.06, respectively; $F(3$, 2432) $=30.443, p<.001)$.

The levels of belongingness were lower for all groups during the stressful time as compared to their reports from the baseline period. Those reporting accessing only informal help showed the lowest reductions in their sense of belongingness during the stressful period (0.91) as compared to those in the no help group (1.74), the professional help only group (1.20), and the professional and informal help group (1.41).

Students who sought only professional help reported the lowest levels of their sense of coherence at baseline (16.78) as compared to those in the no help (18.21), informal help (18.60), and the professional and informal help groups $(17.73)(F(3,2,560)=10.209, p<.001)$. This trend carried over to the stressful period where those seeking only professional help reported the lowest levels of sense of coherence (14.98), as compared to those in the no help (17.44), informal help (18.06), and the professional and informal help groups $(16.73)(F(3,2421)=20.248, p<.001)$. Further, those who only sought professional help reported the largest reduction in their sense of coherence over this period (1.80), as compared to those in the no help (0.77), informal help (0.54), and the professional and informal help groups (1.00).

No differences were found for academic integration and social integration, and the combined social/academic integration across sources of help-seeking. Finally, the participants seeking only informal help reported the highest levels of connection to their university $(M=3.36)$ while those seeking only professional help reported the lowest levels $(M=2.92)$.

\section{DISCUSSION}

International students sought informal sources as their primary means of support when dealing with almost all stressors, and then supplemented with 
professional support as the second highest scenario, rarely seeking only professional help to manage their stressors. Even so, less than $1 / 2$ accessed professional help for some serious concerns such as the suicide of a close person, assaults, and interpersonal violence. These results support the findings of Alavi et al. (2014) indicating that international students tend to turn to informal sources of support and those of Brownson and colleagues (2014) which found informal sources of support served as conduits to professional helping resources. The current findings add to our understanding of where international students turn for support across a wide range of stressors, providing much-needed data to support outreach, prevention, and clinical interventions with these students. The current findings also demonstrate the need to make professional helping resources more accessible to international students, as they underutilize professional support that could help them manage very serious stressors they encounter. In addition, the results also suggest a need to develop peer support training so that international students can seek help from those they are most comfortable with, and then those peers can be trained to talk about the importance of seeking professional help when indicated.

The current findings indicate four areas where students from the different help-seeking groups reported different levels at which the stressors contributed to their overall distress. First, students who accessed professional help for their physical health, emotional health and academic problems all reported that these stressors contributed to their overall distress at higher levels than those seeking only informal sources of support and those not seeking help. Second, those seeking support from a combination of professional and informal sources reported that the contribution of their family problems to their distress was higher than for those seeking only informal or only professional support. These results suggest that, at least for some stressors, international students do turn primarily to professional help when their distress level climbs sufficiently.

A third significant finding lies in an examination of those students not seeking help. For instance, among those international students who did not seek help from anyone to cope with a sexual assault, they rated the contribution of the assault to their overall distress among the highest of any stressor. International students may not know how to seek help when they are a victim of an assault and, even if they do reach out for support, their peers may not know how to best respond and refer them to professional help. They are perhaps influenced by a lack of familiarity with the laws and customs in the United States around what constitutes assault or consent and potentially experience intimidation surrounding navigating the local justice 
system or involving police in their affairs. Additionally, students may find that seeking help for some stressors, such as physical health problems, may be more culturally acceptable. These findings indicate key areas where students are experiencing considerable distress, yet not seeking support. Universities can enhance their outreach efforts to provide information to international students about how victims might seek support, such as where to turn on campus and information about confidentiality, and also how students might support a peer in distress.

Fourth, individuals who sought only informal help ranked among the highest in all the psychological constructs measured such as mindfulness, sense of belonging, sense of coherence, and integration and connection to university among the four help-seeking groups. On the other hand, individuals who sought only professional help ranked the lowest in all the above-mentioned constructs among the four help-seeking groups. No significant differences in these constructs were found between those nonhelp seekers and those seeking both professional help and informal help. It may be that help-seeking is a proxy for the severity of their concerns where it would make sense that those who are struggling most (and hence seeking professional help) are lowest in all of these constructs while those rating their mindfulness, belonging, sense of coherence and university connection higher may find sufficient support through their peers.

The students who sought informal help had statistically higher mindfulness scores than those seeking professional help only or seeking both professional and informal help. As Lim (2013) found that mindfulness mediated the relationship between rumination and help-seeking, individuals who are more mindful may be more observant and non-judgmental to their internal emotions and distress. Thus it may be more likely for them to seek help when needed from various natural sources. This could reduce the likelihood of stress and anxiety accumulation, reducing the need to seek professional help. Mindfulness could serve as a protective factor for students to cope during the time of stress.

Individuals who sought informal help reported the highest levels of their baseline sense of belonging and reported the least drop in the sense of belonging between the baseline and the stressful moment. Individuals who did not seek help reported the largest drop in the sense of belonging between baseline and stressful period. This highlights the importance of enhancing supports in the proximal environment so that students have a high perception of belonging before they encounter significant stressors to help them access such resources during a time of stress. For instance, programs could pair international students with a "buddy" who is from the United 
States as well as connect them with other international students when they enter the university (Andrade, 2006; Campbell, 2011).

Higher baseline sense of belonging and sense of coherence among those seeking informal help was associated with higher levels of belonging and coherence during the stressful time. The informal help-seeking individuals, likely due to their higher levels of belonging and coherence in their environment, were more inclined to seek help when needed from people around them. On the other hand, a lower sense of belonging and coherence were associated with seeking more professional help. It could be that those individuals who do not feel as connected to others and struggle with seeing the world as coherent, do not know where to seek informal help because most of them are far away from families and friends of their home countries. Lacking informal helping resources, they may turn to professional help when they encounter difficult situations.

Interestingly, individuals who feel more connected to their university tended to either not seek help or seek out informal sources. Connection to their university may be a protective factor during the time of stress for international students as they may feel less of a need for support or that they can manage with their informal network of peers. When students note that they feel connected to their university, they may mean they feel connected to their friends rather than the professional help-seeking resources available on campus.

\section{Limitations}

This study has several limitations. First, while participants in the study hail from many countries and world regions, they come primarily from Asia and reside in graduate programs, and so may not necessarily be representative of the international student population of all universities. As international students come from many different places and cultures, caution should be taken when applying the results to a general population of international students. For instance, the international student from Canada likely experiences their campus quite differently than the international student from China. Second, participants were asked to recall and report their level of stress and related questions during a stressful moment in the past year. Thus the results are subject to their ability to recall these memories. Third, we lack information to determine whether some international students may have fully understood the survey items as the researchers intended based upon their language proficiency or cultural influences. 


\section{IMPLICATIONS}

The current study, though with its limitations, has implications for future research, clinical intervention, outreach, and prevention. First, international students from Western and non-Western countries may experience systemic differences in help-seeking behaviors, impacted by differing sociocultural attitudes towards counseling (Dadfar \& Friedlander, 1982), familiarity with counseling services (Lee, 2010; Li \& Kaye, 1998; Russell, Thomson, \& Rosenthal, 2008), and collectivism versus individualism (Kim, 2007). As such, future research might examine differences between international students from Western and non-Western countries of origin to better understand implications for service delivery, whereby universities may tailor their services towards different cultural groups. Second, future research might consider school size in terms of international student help-seeking. For example, a school with an enrollment of 500 students compared with a school with an enrollment of 20,000 students might find differences in helpseeking behaviors and institutional support systems. Future research might also consider the proportion of international students enrolled at particular colleges as international students living and learning with more of their similarly situated peers might differ in terms of their connection to others and their tendency to seek help. Findings from such a study would provide more insight into the help-seeking behaviors of international students across various colleges and help foster the development and implementation of additional support services.

The findings of the current study also have practical implications. University campuses must take the initiative to create a supportive, culturally diverse, and welcoming environment to help international students establish a strong bond and connection with their universities and the peers around them. This is especially important during the initial transition period as international students may encounter a great number of challenges during the transition from their home countries to the United States. Thus, adequate training for faculty and staff on how to handle intercultural communications is crucial. In addition, universities can help domestic students become more sensitive to and aware of, the unique challenges facing international students and how their culture may impact how they choose to cope.

The results of the current study inform outreach and prevention efforts to improve access to professional support on campus by increasing our understanding of the types of stressors international students tend to avoid seeking help for and where they turn when they do seek support. Peer support programs could be particularly effective for international students, 
providing a service that meets their needs for more informal sources of support, while being trained to refer to professional help when indicated. University counseling centers and the office of international students affairs could offer skill-building workshops (such as mindfulness practice or building relationships) to improve students' feelings of belonging, sense of coherence and their connection to the university, which would likely help students cope with stressors and better access informal sources of support. Universities should also enhance access to professional help for international students to support them in managing the many stressors they face as they attempt to acclimate to their new environment.

International students bring a richness to the university experience as others gain exposure to their unique cultures and ways of thinking. Yet international students experience unique stressors and may struggle to receive the help they need to address mental health concerns. Universities can improve the ability of international students to thrive and enhance their contributions by helping students, staff, and faculty better understand the stressors international students experience and how to best connect them with the support they need. Additionally, helping international students build protective factors, such as an increased sense of belonging and sense of coherence, early in their academic experience would likely help them better manage the stressors they will face.

\section{ACKNOWLEDGMENTS}

We wish to thank Adryon Burton Denmark, Elaine, Hess and the Research Consortium of Counseling Centers in Higher Education for their support of this research.

\section{REFERENCES}

Alavi, M., Shafeq, S. M., Geramian, S. M., \& Ninggal, M. T. (2014). International students' mental health and attitude toward counseling centers. Journal of Applied Sciences, 14, 1871-1876.

Andrade, M. S. (2006). International students in English-speaking universities: Adjustment factors. Journal of Research in International Education, 5, 131-154.

Antonovsky, A. (1993). The structure and properties of the sense of coherence scale. Social Science and Medicine, 36, 725-733.

Arthur, N. (1997). Counselling issues with international students. Canadian Journal of Counselling, 31, 259-274. 
Aubrey, R. (1991). International students on campus: A challenge for counselors, medical providers, and clinicians. Smith College Students in Social Work, 62, 20-33.

Bradley, L., Parr, G., Lan, W. Y., Bingi, R., \& Gould, L. J. (1995). Counseling expectations of international students. International Journal for the Advancement of Counseling, 18, 21-31.

Brownson, C., Swanbrow Becker, M., Shadick, R., Jaggars, S. S., \& Nitkin-Kaner, Y. (2014). Suicidal behavior and help seeking among diverse college students. Journal of College Counseling, 17, 116-130.

Campbell, N. (2011). Promoting intercultural contact on campus: A project to connect and engage international and host students. Journal of Studies in International Education, 16, 205-227.

Cho, J., \& Yu, H. (2015). Roles of university support for international students in the United States: Analysis of a systematic model of university identification, university support, and psychological well-being. Journal of Studies in International Education, 19, 11-27.

Dadfar, S., \& Friedlander, M. L. (1982). Differential attitudes of international students toward seeking professional psychological help. Journal of Counseling Psychology, 29, 335-338.

Du, Y., \& Wei, M. (2015). Acculturation, enculturation, social connectedness, and subjective well-being among Chinese international students. The Counseling Psychologist, 43, 299-325.

Feldman, G., Hayes, A., Kumar, S., Greeson, J. \& Laurenceau, J.P. (2007). Mindfulness and emotion regulation: The development and initial validation of the Cognitive and Affective Mindfulness Scale-Revised (CAMS-R). Journal of Psychopathology and Behavioral Assessment, 29, 177-190.

Glass, C. R. (2014). International student adjustment to college: Social networks, acculturation, and leisure. Journal of Park and Recreation Administration, 32, 7-25.

Grayson, J. P. (2007). Sense of coherence, problem freedom, and academic outcomes of Canadian domestic and international students. Quality in Higher Education, 3, 215-236.

Grayson, J. P. (2008). Sense of coherence and academic achievement of domestic and international students: A comparative analysis. Higher Education, 56, 473-492.

Heggins, W. J., III, \& Jackson, J. L. (2003). Understanding the collegiate experience for Asian international students at a midwestern research university. College Student Journal, 37, 379-391.

Hwang, B. J., Bennett, R., \& Beauchemin, J. (2014). International students' utilization of counseling services. College Student Journal, 48, 347-354.

Institute of International Education (IIE). (2017). Fast Facts Open Doors 2015. Retrieved from https://www.iie.org/Why-IIE/Announcements/2017-11-13Open-Doors-2017-Executive-Summary 
Institute of International Education (IIE). (2015). What international students think about U.S. higher education. Retrieved from http://www.iie.org/en/Research-and-Publications/Open-Doors

Kim, B. S. K. (2007). Adherence to Asian and European American cultural values and attitudes toward seeking professional psychological help among Asian American college students. Journal of Counseling Psychology, 54, 474480.

Knight, J. (2003). Updating the definition of internationalization. International Higher Education, 33, 2-3.

Knight, J. (2004). Internationalization remodeled: Definitions, approaches and rationales. Journal of Studies in International Education, 8, 5-31.

Lee, J. J. (2010). International students' experiences and attitudes at a US host institution: Self-reports and future recommendations. Journal of Research in International Education, 9, 66-84.

Li, Y. P., Wong, J., \& Toth, P. (2013). Asian international students' willingness to seek counseling: A mixed-methods study. International Journal for the Advancement of Counselling, 35, 1-15.

Li, R. Y. \& Kaye, M. (1998). Understanding overseas students' concerns and problems.

Journal of Higher Education Policy and Management, 20, 41-50.

Lim, H. A. (2013). The role of non-reactivity in the rumination-help-seeking relationship: Evidence from a cross-sectional study in Singapore. PRISM: USP Undergraduate Journal, 5, 50-59.

Lin, J. C. G. (1996). Counseling college students from Taiwan. In P. Pedersen \& D. Locke (Eds.), Cultural and Diversity Issues in Counseling (pp. 51-53). Greensboro, NC: ERIC/CASS Publications.

Lin, J. G., \& Yi, J. K. (1997). Asian international students' adjustment: Issues and program suggestions. College Student Journal, 31, 473-479.

Mamiseieshvili, K. (2012). International student persistence in U.S. postsecondary institutions. Higher Education, 64, 1-17.

Masuda, A., Wendell, J. W., Chou, Y., \& Feinstein, A. B. (2010). Relationships among self-concealment, mindfulness and negative psychological outcomes in Asian American and European American college students. International Journal for the Advancement of Counselling, 32, 165-177.

Mitchell, S. L., Greenwood, A. K., \& Guglielmi, M. C. (2007). Utilization of counseling services: Comparing international and U.S. college students. Journal of College Counseling, 10, 117-129.

Mori, S. (2000). Addressing the mental health concerns of international students. Journal of Counseling \& Development, 78, 137-144.

Nillson, J. E., Berkel, L. A., Flores, L. Y., \& Lucas, M. S. (2004). Utilization rate and presenting concerns of international students at a university counseling center: Implications for outreach programming. Journal of College Student Psychotherapy, 19, 49-59. 
Olivas, M., \& Li, C. (2006). Understanding stressors of international students in higher education: What college counselors and personnel need to know. Journal of Instructional Psychology, 33, 217-222.

Pedersen, P. (1991). Counseling international students: A clinician's comments. The Counseling Psychologist, 19, 10-58.

Poyrazli, S. (2015). Psychological symptoms and concerns experienced by international students: Outreach implications for counseling centers. Journal of International Students, 5, 306-312.

Poyrazli, S., \& Kavanaugh, P. (2006). Marital status, ethnicity, academic achievement, and adjustment strains: The case of graduate international students. College Student Journal, 40, 767-780.

Rickwood, D., Deane, F. P., Wilson, C. J., \& Ciarrochi, J. (2005). Young people's help-seeking for mental health problems. Australian Journal for the Advancement of Mental Health, 4, 1-34.

Russell, J., Thomson, G., \& Rosenthal, D. (2008). International student use of university health and counselling services. Higher Education, 56, 59-75.

Sanderson, G. (2008). A foundation for the internationalization of the academic Self. Journal of Studies in International Education, 12, 276-307.

Sabouripour, F., \& Roslan, S. (2015). Resilience, optimism, and social support among international students. Asian Social Science, 11, 159-170.

Tinto, V. (1998). Stages of student departure: Reflections on the longitudinal character of student leaving. The Journal of Higher Education, 59, 438455.

Wilson, C. J., Deane, F. P., Biro, V., \& Ciarrochi, J. (2003). Youth barriers to helpseeking and referral from general practitioners. A Report of Research Supported by the National Health and Medical Research Council of Australia, Illawarra Division of General Practice and University of Wollongong, Wollongong, Australia.

Wisdom, J. P., Clarke, G. N., \& Green, C. A. (2006). What teens want: Barriers to seeking care for depression. Administration and Policy in Mental Health and Mental Health Services Research, 33, 133-145.

Yan, K., \& Berliner, D. C. (2011). An examination of individual level factors in stress and coping processes: Perspectives of Chinese international students in the United States. Journal of College Student Development, 5, 523-542.

Yi, J. K., Lin, J., \& Kishimoto, Y. (2003). Utilization of counseling services by international students. Journal of Instructional Psychology, 30, 333-342.

Zhang, N., \& Dixon, D. N. (2003). Acculturation and attitudes of Asian international students toward seeking psychological help. Journal of Multicultural Counseling and Development, 31, 205-223.

MARTIN A. SWANBROW BECKER, PhD, is an Assistant Professor in the Department of Educational Psychology and Learning Systems, Florida State University. His major research interests lie in the areas of college student suicide prevention, stress, coping and resilience. Email: mswanbrowbecker@fsu.edu 
SHENGLI DONG, $\mathrm{PhD}$, is an Associate Professor in the Department of Educational Psychology and Learning Systems, Florida State University. His major research interests lie in the areas of workplace and academic accomodations, transition issues, mindfulness and multicultural counseling and social justice in counseling. Email: sdong3@fsu.edu

JULIA KRONHOLZ, PhD, is a licensed psychologist in Salt Lake City, Utah. Her major research interests include college student success and resilience, career choice and career decision-making, and psychological assessment and evaluation. Email: julia.kronholz.phd@gmail.com

CHRIS BROWSON, PhD, is an Associate Vice President for Student Affairs, Director of the Counseling and Mental Health Center, and Clinical Associate Professor in Educational Psychology, The University of Texas at Austin. His major research interests include college student suicide prevention, the intersection of mental health and academic success, and the integration of mental health into primary care. Email: cbrownson@austin.utexas.edu Accepted for publication: December 8, 2017 